\title{
IMPLICATIONS OF THE ENVIRONMENTAL IMPACT ASSESSMENT REGULATIONS ON THE AGRICULTURAL SECTOR IN THE OVERBERG DISTRICT IN THE WESTERN CAPE FOR EMERGING FARMERS
}

\author{
Jepthas, G. ${ }^{1}$ and Swanepoel, J. W. ${ }^{2}$
}

Correspondence author: G. Jepthas. Email: GrantJ@elsenburg.com

\begin{abstract}
The Environmental Impact Assessment (EIA) is a tool that can assist with decision making to produce food sustainably and still look at protecting or preserving natural resources. The Overberg District, the chosen study area, is located in the southern parts of the Western Cape Province in South Africa and the area is rich in agricultural activities. The EIA regulations can affect future agricultural activities for both commercial and emerging farmers. For this study, emerging farmers were chosen as many of these farmers are developing or expanding their farming enterprises and the high costs of EIAs can result in financial implications for these farmers. The purpose of the study was to determine the effects of EIA regulations on the emerging farmers in the Overberg region. Furthermore, the study aims to assess the interpretation of extension staff and farmers regarding EIA regulations and its importance for agriculture. In addition, the study seeks to propose methods to improve the knowledge and awareness of EIA regulations amongst farmers and extension staff by creating a better understanding regarding the EIA process. To successfully meet the objectives of this study, structured questionnaires were administered to 30 farmers and 29 extension officers. The study found that EIA regulations do impact farming operations and that many farmers also lack knowledge regarding EIA regulations.
\end{abstract}

Keywords: Emerging farmer, Environmental Impact Assessment (EIA) regulations, Extension officer

\section{INTRODUCTION}

The agriculture industry in the Western Cape plays an important role to ensure food security in the country. It creates employment, especially in rural areas, and can be seen as an instrument to attract foreign investments (Vink et al, 2003). The Overberg District is located in the southern parts of the Western Cape. The Overberg District has diverse commodities in the agricultural landscape of South Africa, which consist of livestock, sheep, viticulture, fruit, grain, oil seed crops, teas, vegetables, and pig farming (Department of Rural Development and Land Reform (DRDLR), 2017). With these numerous commodities, farmers can easily violate the Environmental Impact Assessment (EIA) regulations and the relevant authorities that govern these regulations can give out major penalties. The EIA regulations can be violated by undertaking the following: cultivation of virgin land, implementation of dams, laying of pipelines, and work employ in rivers on farms.

\footnotetext{
${ }^{1}$ Western Cape Department of Agriculture, Elsenburg, Western Cape, +27 (0)28 425 4819, grantj@elsenburg.com ${ }^{2}$ Centre for Sustainable Agriculture, Faculty of Natural and Agricultural Sciences, University of the Free State, Bloemfontein, +27 (0)51401 2163, SwanepoelJW@ufs.ac.za
} 
Due to the time constraints and high implementation cost involved in the EIA process, it can have a negative impact on development taking place on the farm level. In contrast, it can protect farmers and the agricultural sector from large developments that are taking place that have a negative influence on the agricultural sector. Over the last three decades, the EIA has been seen as one of the most successfully and widely adopted environmental policy instruments (Sandham, Hoffmann \& Retief, 2008). The EIA process can be described as a method of evaluating the consequences that will occur if certain actions are undertaken (Wood, 2003). The EIA process can be used to evaluate the environmental consequences for a proposed project and create action plans that can reduce the impact that the project has on the environment. In addition, it will ensure that these action plans are implemented during commencement of the project (Glasson, Therivel \& Chadwick, 2005).

The EIA process has been implemented in various countries across the world, but it was first started in the United States of America (USA) due to the concern of the public of the dangerous consequences that large projects had on the environment (Singh, 2007). Although the EIA process has begun in developed countries, developing countries have also adapted to it over the years (Lee, 2000). The EIA regulations were first introduced in South Africa when it was incorporated in the Environmental Conservation Act (ECA) 73 of 1989, and terms of section 21 and 26 of this Act on September 1997 (Osborne, 2015). The ECA of 1989 was phased out and followed by the National Environment Management Act (NEMA) of 1998 (Osborne, 2015).

The EIA regulations have gone through many changes over the years in South Africa, where the process has been strengthened with various legislative changes, making it more accessible and reasonable for implementation (Montgomery, 2015). There are also two other laws that can be affected by development in the agriculture sector, namely the Conservation of Agriculture Resource Act (CARA) No. 43 of 1983, and the Water Users License Authorisation. These laws can sometimes be confusing, difficult to interpret and time consuming, with major implementation costs.

For the purpose of this study, three objectives were highlighted. Firstly, to determine the effects of EIA regulations on the emerging farmers in the Overberg region. Secondly, to assess the interpretation of extension staff and farmers regarding the EIA regulations and its importance for agriculture. Thirdly, to propose methods to improve the knowledge and awareness of EIA regulations amongst farmers and extension staff by creating a better understanding regarding the EIA process.

\section{METHODOLOGY}

The Overberg region was chosen as the study area mainly due to the diverse agricultural commodities in the district. The district also has a number of emerging farmers at various locations. As emerging farmers and extension officers are at the forefront of agricultural development in the district, these two groups of individuals were chosen to take part in the study. The reason as to why extension staff formed part of the study was because they are the link between the farmers and other programmes in government departments that specialise in the field of environmental protection. Extension staff are also in a position to provide guidance to farmers and have access to funding. The farmers formed part of this study as they are the individuals that are directly affected by EIA regulations. 
Interviews were conducted to determine the impact of EIA regulations on the agricultural industry from a management perspective. Thus, data were collected through the use of structured questionnaires and interviews. Questionnaires were randomly distributed to farmers in the Overberg region. However, the extension staff in the Overberg District is small in number, therefore, the entire Western Cape extension staff participated in this study. Data were collected from 30 farmers and 29 extension staff members.

\section{RESULTS AND DISCUSSION}

\subsection{Demographics}

This section deals with various demographic characteristics such as gender, age, education, work experience, farming experience, and to which enterprises they are associated.

\subsubsection{Extension officers}

The gender of the extension officials that took part in the study consisted of $37.9 \%$ females and $62.1 \%$ males. The age profiles of the extension officers are $20.6 \%$ (20-35 years), $65.5 \%$ (3650 years) and $13.8 \%$ (51 years or older). The $13.8 \%$ assumedly are extension officers with experience of more than 20 years as specified in Table 1, and this can also give an indication that experience and skills will be lost due to retirement. Furthermore, the extension officers that participated in the study have a great amount of experience in extension as shown in Table 1. The education levels of extension officers ranges between National Diplomas, Bachelors, Honours, Masters and Doctoral degrees. The enterprises that the various extension officers provide advice for are as follows; $72.4 \%$ livestock, $44.8 \%$ sheep, $24.1 \%$ grain, $65.5 \%$ vegetables, $27.6 \%$ fruit, and $31 \%$ other (which include honey bush tea, nuts and bees).

Table 1: Extension officers' number of years' experience in providing extension service

\begin{tabular}{|l|c|c|}
\hline Extension advisory experienc & Response Percent \\
\hline Less than 5 years & 6 & $20,7 \%$ \\
\hline $5-9 y e a r s$ & 8 & $27,6 \%$ \\
\hline $10-19 y e a r s$ & 11 & $37,9 \%$ \\
\hline More than 20 years & 4 & $13,8 \%$ \\
\hline Total & $\mathbf{2 9}$ & $\mathbf{1 0 0 , 0 \%}$ \\
\hline
\end{tabular}

\subsubsection{Farmers}

The gender of the farmers that participated in the study consists of $13.3 \%$ females and $86.7 \%$ males, and from these percentages it can be deduced that men are dominating farming in this region. The age profiles of the farmers that took part in the study are 13.3\% (20-35 years), 30\% (36-50 years) and 56.7\% (51years or older). From this data, it can be reasoned that farming in the region is not appealing to the youth and more appealing to the older generation. Furthermore, the group have a substantial amount of farming experience as $90 \%$ of the participants have more than four years of farming experience as can be seen in Table 2. 
Table 2: Farmers' number of years' experience in farming

\begin{tabular}{|l|c|c|}
\hline Farming experience & Response & Percent \\
\hline Less than 1 year & 1 & $3,3 \%$ \\
\hline $1-3$ years & 2 & $6,7 \%$ \\
\hline 4-6 years & 6 & $20,0 \%$ \\
\hline 7-9 years & 5 & $16,7 \%$ \\
\hline 10 years or more & 16 & $53,3 \%$ \\
\hline Total & $\mathbf{3 0}$ & $\mathbf{1 0 0 , 0}$ \\
\hline
\end{tabular}

The educational levels of the farmers are as follows: $13.3 \%$ (Grade R-Grade 9), 43.3\% (Grade 9-Grade 12 ), $16.7 \%$ matriculated, $13.3 \%$ national certificate and $13.3 \%$ tertiary qualifications. From these education levels, it can be deduced that most of the farmers can read and write. In the agricultural sector, education is a crucial aspect as it can assist with the understanding and articulating of issues regarding the sector (Sebeho, 2017). The enterprises of the farmers that took part in the study was $66.7 \%$ livestock, $46.7 \%$ sheep, $36.7 \%$ grain, and $46.7 \%$ other enterprises which they have indicated to include dairy and rooibos tea. The wide variety of enterprises that the farmers have also show that the farmers can be exposed to a wide range of different listing activities (South African Government Gazette, 2017a; South African Government Gazette, 2017b; South African Government Gazette, 2017c).

Overall, both groups of farmers and extension officers have a wide and diverse range of experience in the agriculture sector and it is also spread over numerous years. This experience in farming can be of great benefit for this study as the EIA was implemented in South Africa in the 1970's and various regime changes have taken place since then (Montgomery, 2015; Wood, 1999). This can also be complemented with a wide amount of enterprises that the extension officers specialise in and diverse enterprises which the farmers practice. This is supported by WESGRO (2014) which states that the Western Cape has a diverse agricultural sector which has 11 commodities that contribute to the sector.

\subsection{Effects of EIA regulations on farming}

In order to determine the effects that the EIA regulations have on farming, various questions were posed to the participants including how these regulations influenced different projects of the extension officials, impacted production levels, as well as the origins of EIA regulation activities triggered. The EIA regulations can have various effects on farming, which include economic, social and natural resource factors. The economic analysis of the environmental impact of a project is critical during the preparation phase to determine whether the project's net benefit will be greater than the alternative even in the event of a non-project scenario (James, 1994). Thus, by having various alternatives during the planning phase it can assist with decision-making (Tshabangu, 2009) and this can reduce the impact that the agricultural project has on the environment. Of the farmers that took part in the study, $48.3 \%$ have been negatively influenced by the EIA regulations as it restricted the planning of new enterprises.

The farmers were asked if the EIA regulations affected their production levels and 12 of the farmers $(40 \%)$ said yes, while 18 farmers $(60 \%)$ were not influenced by the regulations. The 12 farmers whose production levels decreased, indicated that they could not cultivate virgin land due to the EIA regulations, except one farmer who indicated the production level losses were due to loss of fertile soil as the farmer could not control erosion. 
Furthermore, the extension officers were also asked if the EIA regulations affected the production levels of their projects, and the resultant percentages were more or less balanced as $48.3 \%$ of projects production levels declined, while the other $51.7 \%$ did not have any effects on their projects. The decline in production levels can be detrimental to the development of the farmers as the majority of the farmers invest their profits in farming and some use it for home consumption. Figure 1 displays the causes of EIA regulations' impact on the farmers' production levels which included $71.4 \%$ cultivation of virgin land, $21.4 \%$ utilisation of water, $14.3 \%$ pollution associated, and $21.4 \%$ other (this included intense holding of animals and keeping more rabbits than what is required by listing notice).

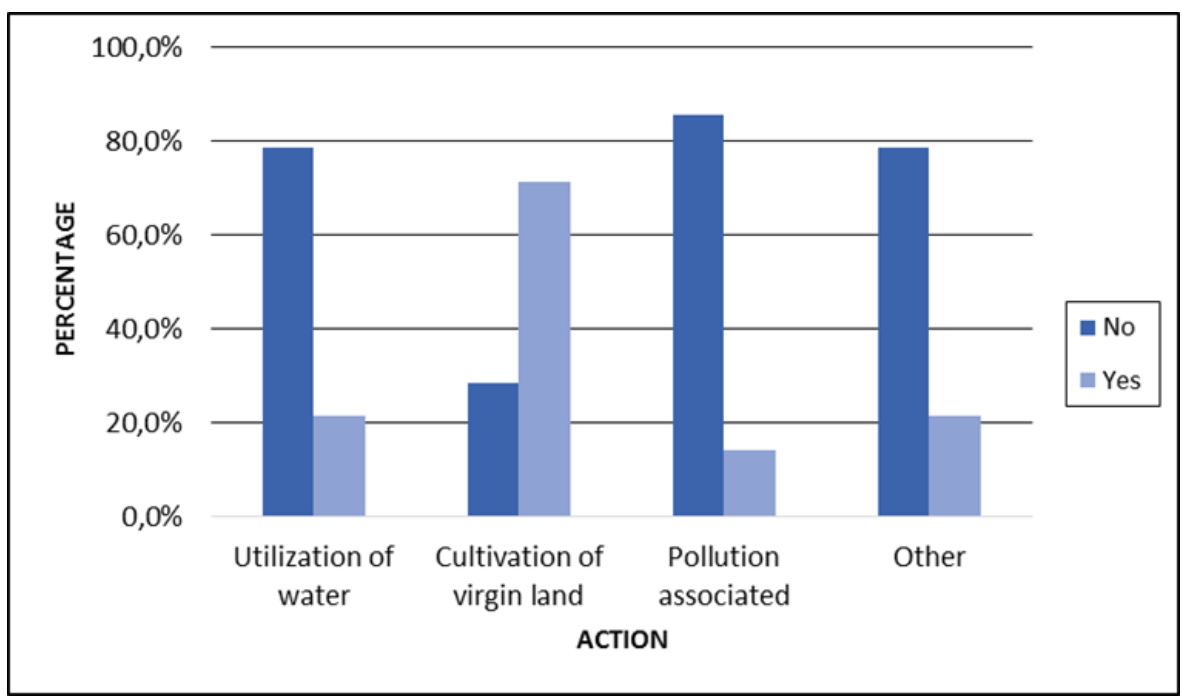

Figure 1: The causes of EIA regulations' impact on the farmers' production levels

This has resulted in a decrease in crop yields and farmers could not increase their grazing capacity due to the restriction of the production levels. There is a high percentage of projects that were influenced due to restrictions regarding the cultivation of virgin land, which may include limitations in planting cash crops such as grain, canola and planting of fodder to increase the grazing capacity of farming unit. In South Africa, the agriculture sector has the greatest impact in habitat loss across the country, affecting biodiversity patterns that are due to the intense cultivation as well as poorly protected lowlands of the Western Cape (Cowling et $a l, 1999)$. Furthermore, when farmers complete the application for the EIA process, it can take up to 12-18 months depending on the triggered listed activities and this can lead to seasonal losses for farmers (Montgomery, 2015). Moreover, EIA regulations have also restricted the planning or proceeding of some of the extension officials' projects as $58.6 \%$ have seen difficulties with the implementation of projects. Most of the projects were restricted due to the cultivation of virgin vegetation and farmers could not expand their farming activities.

\subsection{Interpretation of EIA regulations and importance to agriculture}

The EIA regulations can be a very complex subject and very difficult to interpret. To determine both farmers and extension officers' level of understanding, as well as penalties faced for noncompliance of EIA regulations, a number of questions were posed to the participants. With regards to their level of understanding with respect to the EIA regulations, 53.3\% of the farmers are familiar with the EIA regulations, whereas $89.7 \%$ of the extension officials are familiar. The majority of those who are familiar with the EIA regulations have minimal or partial 
understanding (Table 3 and 4). From the farmers' perspective, these numbers show that there is a lack of understanding of the EIA regulations.

Table 3: Level of understanding of EIA regulations for farmers

\begin{tabular}{|l|c|c|}
\hline Level of understanding & Response & Percent \\
\hline Minimal understanding & 10 & $62,5 \%$ \\
\hline Partial understanding & 4 & $25,0 \%$ \\
\hline Fully understand & 2 & $12,5 \%$ \\
\hline Total & $\mathbf{1 6}$ & $\mathbf{1 0 0 , 0} \%$ \\
\hline
\end{tabular}

Table 4: Level of understanding of EIA regulations for extension officers

\begin{tabular}{|l|c|c|}
\hline Level of understanding & Response & Percent \\
\hline Minimal understanding & 10 & $38,5 \%$ \\
\hline Partial understanding & 11 & $42,3 \%$ \\
\hline Fully understand & 5 & $19,2 \%$ \\
\hline Total & $\mathbf{2 6}$ & $\mathbf{1 0 0 , 0} \%$ \\
\hline
\end{tabular}

Only $53.3 \%$ of the farmers are aware of penalties that farmers can face for non-compliance with EIA regulations, while $89.7 \%$ of the extension staff said that they are aware of penalties associated with non-compliance. The participants were also asked if they are aware of the listing notices of the EIA regulation; $20.7 \%$ of the farmers said yes and $79.3 \%$ said no, while $69 \%$ of the extension staff said yes and the other $31 \%$ said no.

It can be also be noted that the extension officers have room for improvement, as only five extension officers fully understand EIA regulations as shown in Table 4. It is expected that extension officers be able to provide information to emerging farmers with regards to EIA regulations through advisory services. Emerging farmers often do not have access to updated information and extension officers are often the sole means of transferring information. The EIA regulations have three different types of listing notices, namely listing notice 1 (GNNo.R. 327), listing notice 2 (GNNo.R 324) and listing notice 3 (GNNo.R 324). Under these listings are the respective activities which these farmers should comply with (South African Government Gazette, 2017a; South African Government Gazette, 2017b; South African Government Gazette, 2017c). By understanding these listing notices, the farmers and extension officials will know what activities they should comply with on a project and farming level (South African Government Gazette, 2017a; South African Government Gazette, 2017b; South African Government Gazette, 2017c).

Of all the farmers that participated in the study, only one farmer was guilty of non-compliance with the EIA regulations as the farmer had cultivated virgin land unlawfully, however, the penalty received was not elaborated on. From the extension officers' projects, six farmers were guilty of non-compliance of the EIA regulations. Five of the farmers were guilty of the cultivation of virgin land and one farmer kept more than 500 rabbits on the farm. From the farmers that participated in the study, only $43.3 \%$ had received assistance from the extension officers regarding the EIA regulations. Of the farmers who had received assistance, only 9 farmers said that it supported them with planning of their farming business. When planning projects, $93.1 \%$ of extension officials take into consideration the EIA regulations. By taking 
into account the EIA regulations during planning, it will prevent farmers from breaking the law and it can also lead to more sustainable projects. A large percentage (86.2\%) of extension staff indicated that they have given advice to farmers regarding the EIA regulations as depicted in Figure 2. This result also demonstrates that extension officials consider EIA regulations when implementing projects. The majority of the advice given was cultivation of land advice for grain farmers, increasing grazing capacity of the farm, or the establishment of new orchards.

\section{Extension Officers providing EIA advice to farmers}

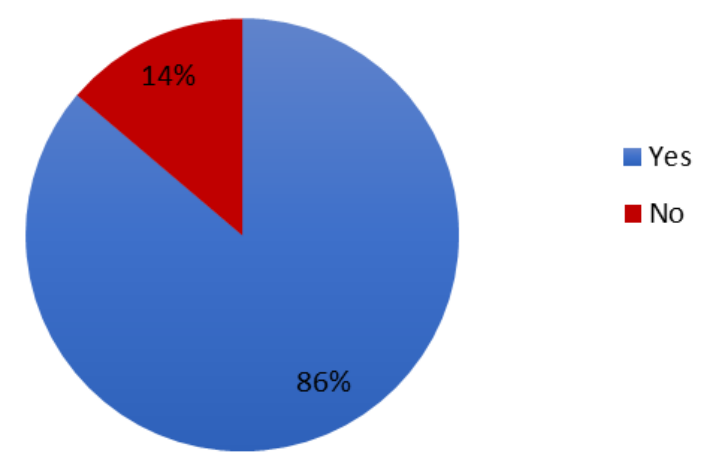

Figure 2: The percentage of extension officers that provided advice regarding the EIA regulations

One of the findings of the study was that the farmers and extension staff consider the EIA regulations in the agricultural environment to be very important as $86 \%$ of the farmers have agreed to its significance and $96.2 \%$ of the extension officials agreed that EIA regulations are important. Many of the farmers and extension officers believe that EIA can be utilised to conserve the natural environment and to limit illegal activities occurring. By taking it into consideration when planning projects, EIA regulations can create sustainable farming projects which future generations could benefit from.

\subsection{Awareness of EIA regulations}

In order to determine the knowledge and awareness of EIA regulations amongst farmers and extension officers, they were questioned about whether they received training, and their preferred methods to create awareness on the subject. To improve the knowledge and understanding amongst farmers and extension officers, various avenues should be looked into. Figure 3 displays the farmers' preferred methods of creating awareness with regards to EIA.

Farm visits was the highest with $60 \%$, as farmers can show the environmental case officer the plans that he/ she wants to implement on the farm. Farmers normally do not have much free time and farm visits can be more appropriate and face-to-face interaction is better amongst the different parties. Creating awareness amongst farmers by means of farmers days was the second preferred choice with $56.7 \%$. This option can be seen as viable as farmers are familiar with these farmers days, which are hosted by the Western Cape Department of Agriculture (WCDOA). Organised agriculture, for example Grain SA and African Farmers' Association of 
South Africa Organisation (AFASA), also host farmers days on a regular basis. Practical advice can be given to groups of farmers at the same time and it can create an environment of information sharing amongst farmers and officials of the Department of Environmental Affairs Development and Planning (DEADP).

With regards to training of extension officers, $30 \%$ of the farmers believe extension officials require training. This percentage is quite low since $89.7 \%$ of the officials are familiar with the EIA regulations. It can also be due to the fact that the farmers do not expect the extension officials to assist them with EIA complications, but rather with other farming advice. Sending monthly newsletters was one of the lowest supported options with only $30 \%$ of the farmers wanting to be informed using this method. A few of the reasons why this option has a low percentage may be due to the fact that farmers are located in remote areas and some of them do not have access to email facilities. Another option to overcome this issue is to print the newsletters and translate them into the farmers' language.

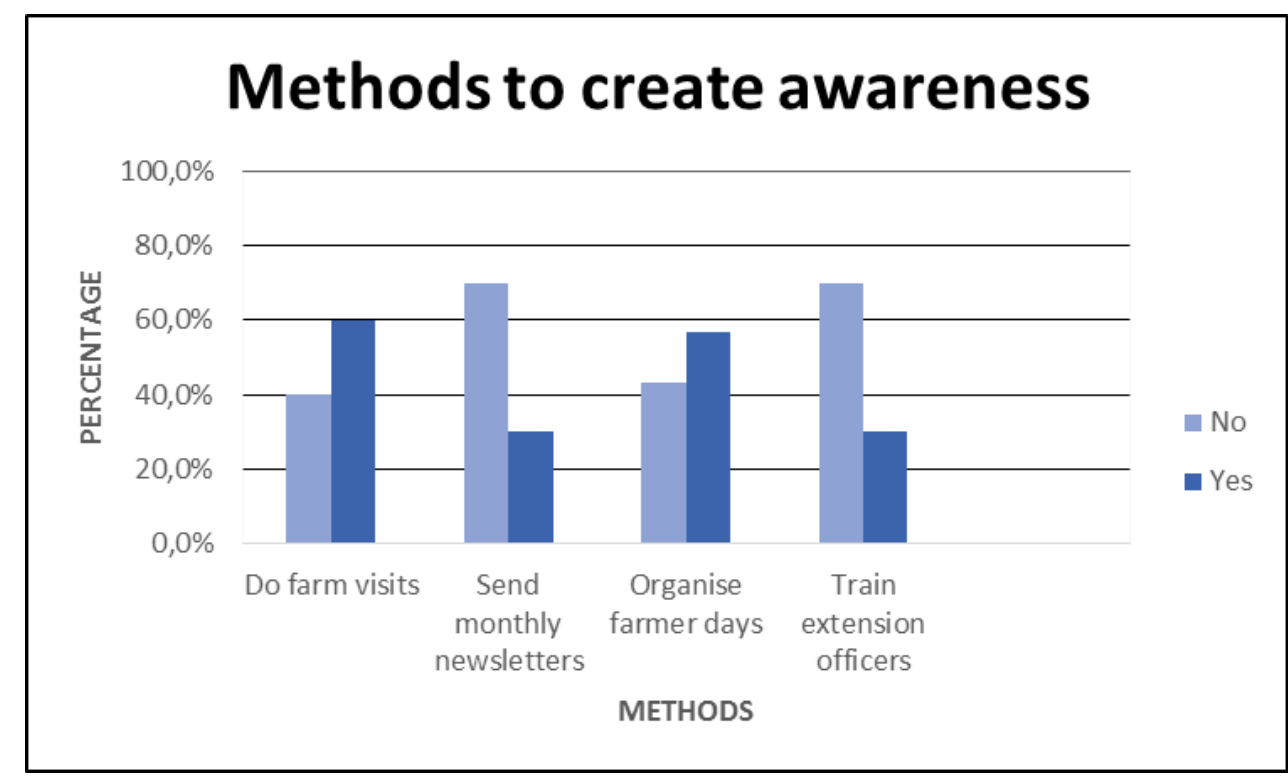

Figure 3: Methods that should be employed to create awareness regarding EIA regulations

One of the methods to improve knowledge and interpretation of farmers and extension officers can be through training, for example workshops, block sessions and strategic sessions. By providing training to extension staff, it can be of great assistance as they are normally the people who work closely with farmers and provide advice to farmers on a daily basis. 


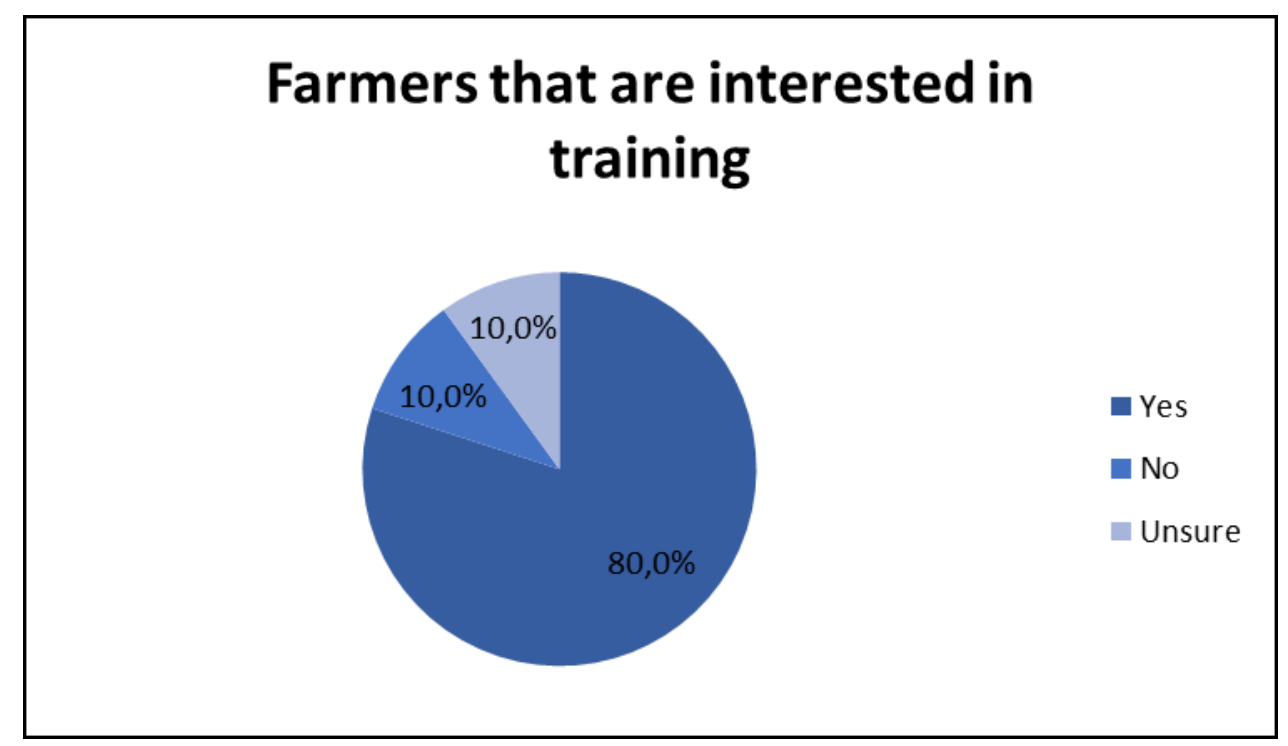

Figure 4: The percentage of farmers that are interested in EIA training

The extension staff that participated in the study indicated that only $20.7 \%$ of them have received training with regards to EIA regulations. Of the extension officers that did not receive training, $89.3 \%$ indicated that they would like to receive some sort of training. Furthermore, $80 \%$ of the farmers have shown an interest in EIA regulations training (Figure 4). It can be perceived that both farmers and extension officials are interested in training due to the high percentages and would like to increase their knowledge around the EIA issue.

The extension officers and farmers indicated that they would like to receive training regarding the laws and aspects revolving around the EIA legislation, specifically associated to agriculture. There are also short courses provided by various tertiary institutions that can assist the extension officers with understanding these EIA regulations. The Extension Recovery Plan (ERP) is also in place to provide support with the development of extension officials (Department of Agriculture, Forestry and Fisheries (DAFF), 2011). The ERP is an initiative by DAFF to improve the extension and advisory services in South Africa (DAFF, 2011). Terblanche and Willemse (2009) stated that through proper alignment of policies and initiatives, training of extension officials, and by making use of resources and skills of the private sector and tertiary institutions, government can be assisted to provide extension to emerging and commercial farmers. Just over half of the farmers who participated in the study (55.2\%) acquire assistance from a mentor. The mentors are normally commercial farmers that may have some background knowledge regarding EIA regulations or have encountered the regulations at least once during their farming years. The mentoring of emerging farmers by commercial farmers can also be an effective tool to train emerging farmers (Ortmann, 2005).

\section{CONCLUSION AND RECOMMENDATIONS}

From the research that was conducted, EIA regulations was shown to affect farmers in the Overberg District. This impact from EIA regulations did reduce the production of some of the farmers that took part in the study. The research also shows that many of the farmers that took part in the study have people employed on the farm and a decline in the production levels can be detrimental to the employment rate of the Overberg region. 
Most of the extension officials that participated in the study have some background knowledge about the EIA regulations, as most of them are aware of it. However, there were only a few extension officers that fully understood the EIA regulations. The extension officers in some instances gave advice to their clients regarding the EIA issues, cultivation of land, implementation of a slaughtering facility and water related issues. Their projects were influenced by EIA regulations and led them to automatically gain knowledge regarding EIA regulations.

The data also suggested that the extension officials consider the EIA regulations when planning their projects. From the farmers' perspective, only half of them are familiar with the EIA regulations. This low amount can have negative effects on the environment and on the agricultural sector. It can also lead to penalties that can result in financial difficulties for the emerging farmers. Both farmers and extension officers consider the EIA regulations as important to the agriculture sector. Their reasoning behind this is that it can assist them to control degradation of natural resources and decision-making. By taking the EIA regulations into consideration in the planning of the farming operations and practices, it could lead to sustainable farming.

Most of the farmers that participated in this study are interested in training and are willing to increase their knowledge regarding the EIA regulations. From the research that was done, most of the farmers are at ease with farmers' days and site visits as means to create awareness amongst farmers. Furthermore, the research shows that not many farmers attain assistance from mentors, which can be beneficial to assist emerging farmers with decision-making regarding the EIA regulations. With respect to the extension officers, it is important for them to increase their knowledge around EIA issues, as they are the key for transferring information to farmers as they provide advice to farmers on a daily basis. The methods that were identified to increase the awareness and assistance of EIA issues around extension officers included better coordination amongst internal programmes at their department and with other governmental departments and the incorporation of environmental consultants where workshops and presentations can be held with extension officers.

\section{REFERENCES}

COWLING, R.M., PRESSEY, R.L., LOMBARD, A.T., HEIJNIS, C.E., RICHARDSON, D.M. \& COLE, N., 1999. Framework for a conservation plan for the Cape Floristic Region, South Africa. IPC Report No. 9902. Stellenbosch, South Africa.

DEPARTMENT OF AGRICULTURE, FORESTRY AND FISHERIES (DAFF), 2011. National framework for extension recovery plan. Pretoria, South Africa.

DEPARTMENT OF RURAL DEVELOPEMENT \& LAND REFORM (DRDLR), 2017. Sector plan: Overberg district rural development plan. Pretoria, South Africa.

GLASSON, J., THERIVEL, R. \& CHADWICK, A., 2005. Introduction to environmental impact assessment. $3^{\text {rd }}$ ed. Routledge: Abingdon.

JAMES, D., 1994. The application of economic techniques in environmental impact assessment. Netherlands: Kluwer Academic Publishers. 
LEE, N., 2000. Environmental assessment in its developmental and regulatory context. In Environmental assessment in developing and transitional countries (pp.13-33). Chichester: John Wiley and Sons.

MONTGOMERY, D.S., 2015. The efficacy of environmental impact assessment on development proposals with respect to cost and time in South Africa: A three case study review. MSc Thesis, University of Witwatersrand.

ORTMANN, G.F., 2005. Promoting the competitiveness of South African agriculture in a dynamic economic and political environment. Agrekon, 44(3):286-320.

OSBORNE, B.N., 2015. A critical evaluation of the concept of sustainable development as applied in the legislation governing environmental impact assessments in South Africa (Case studies: Housing developments). D-Tech thesis, Cape Peninsula University of Technology.

SANDHAM, L.A., HOFFMANN, A.R. \& RETIEF, F.P., 2008. Reflections on the quality of mining EIA reports in South Africa. J. South Afr. Inst. Min. Metall., 108(11):701-706.

SEBEHO, M.A., 2017. Perceptions and attitude of farmers and extensionists towards extension service delivery in the Free State Province, South Africa. PhD Thesis, University of Pretoria.

SINGH, G., 2007. To study the inception and evolution of environmental impact assessment in the world and in India and to analyze and comment upon the environmental clearance process in the country. PhD Thesis, University of Delhi.

SOUTH AFRICAN GOVERNMENT GAZETTE, 2017a. List of activities and competent authorities identified in terms of sections 24 and 24D of the National Environmental Management Act, 1998. Title No. 38282, Notice R324. Pretoria.

SOUTH AFRICAN GOVERNMENT GAZETTE, 2017b. List of activities and competent authorities identified in terms of sections 24 and 24D of the National Environmental Management Act, 1998. Title No. 38282, Notice R325. Pretoria.

SOUTH AFRICAN GOVERNMENT GAZETTE, 2017c. List of activities and competent authorities identified in terms of sections 24 and 24D of the National Environmental Management Act, 1998. Title No. 38282, Notice R327. Pretoria.

TERBLANCHE, L. \& WILLEMSE, B.J., 2009. Investigation into farmer controlled businesses in South Africa: Options and lessons learned. National Agricultural Marketing Council Report. Bloemfontein, South Africa.

TSHABANGU, L., 2009. An economic analysis in the context of environmental impact assessment of an irrigation project in Gutu District, Zimbabwe. MSc Thesis, University of the Free State.

VINK, E.T., RABAGO, K.R., GLASSNER, D.A. \& GRUBER, P.R., 2003. Applications of life cycle assessment to NatureWorks ${ }^{\mathrm{TM}}$ polylactide (PLA) production. Polym. Degrad. Stabil., 80(3):403-419.

WESGRO, 2014. Western Cape contribution to agriculture huge. Available from: https://www.knysnaplettherald.com/News/Article/AgriEco/western-cape-contributionto-agriculture-huge-20170711

WOOD, C., 1999. Pastiche or postiche? Environmental impact assessment in South Africa. S. Afr. Geogr. J., 81(1):52-59. 
S. Afr. J. Agric. Ext.

Vol. 47 No. 2, 2019: 128 - 139

http://dx.doi.org/10.17159/2413-3221/2019/v47n2a509
Jepthas, Swanepoel

(License: CC BY 4.0)

WOOD, C., 2003. Environmental impact assessment: A comparative review. $2^{\text {nd }}$ ed. England: Pearson Education. 